HARING, C., FleischHACKER, W. W., SChett, P., et al (1990) Influence of patient-related variables on clozapine levels. American Journal of Psychiatry. 147. 1471-1475.

-. MEISE, M., HUMPEL, C.. et al (1989) Dose-related plasma levels of clozapine: influence of smoking behaviour, sex and age. Psychopharmacology, 99, S38-540.

-. NEUDORFER, C.. SCHWrTZER, J., et al (1993) EEG alterations in patients treated with clozapine in relation to plasma levels. Psychopharmacology. 114, 97-100.

HASEGAWA, M., GUTIERREZ-EsteINOU, R., WAY, L., et al (1993) Relationship between clinical efficacy and clozapine concentrations in plasma in schizophrenia: effect of smoking. Journal of Clinical Psychopharmacology. 13. 383-390.

KANE, J., COOPER, T. D., SACHAR, E. J., et al (1981) Clozapine: plasma levels and prolactin response. Psychopharmacology. 73, 184-187.

KRONIG, M. H., MUNNE, R. A., SZYMANSK, S., et al (1995) Plasma clozapine levels and clinical response for treatment-refractory schizophrenic patients. American Journal of Psychiatry, 162, 179-182.

Miler, D. D., Fleming, F., Holman, T. L. . et al (1994) Plasma clozapine concentrations as a predictor of clinical response: a follow-up study. Journal of Clinical Psychiatry. 65(9, suppl. B), 117-121.

PERRY, P. J., MiLLer, D. D., ARNDT, S. V., et al (1991) Clozapine and norclozapine plasma concentrations and clinical response of treatment refractory schizophrenic patients. American Joumal of Psychiatry, 148. 231-235.
Piscrtelu. S. C., Frazaer, J. A., MCKenNa, K., et al (1994) Plasma clozapine and haloperidol concentrations in adolescents with childhood-onset schizophrenia: association with response. Journal of Clinical Psychiatry. 85(9, suppl. B), 94-97.

Pollack. S., Leberman, J., KLeiner, D., et al (1993) High plasma clozapine levels in tardive dyskinesia. Psychopharmacology Bulletin, 29, 257-262.

POTKIN, S. G. BERA, R. Gulasekaram, B. et al (1994) Plasma clozapine concentrations predict clinical response in treatment-resistant schizophrenia. Journal of Clinical Psychiatry. 65(9. suppl. B). 133-136.

Rattasuo, V., Lehtovara, R., Huttunen, M. O. (1993) Carbamazepine and plasma levels of carbamazepine. American Joumal of Psychiatry, 160, 169.

Simpson G. M. \& COOPER. T. A. (1978) Clozapine plasma levels and convulsions. American Journal of Psychiatry. 136. 99-100

THORUP. M. \& FOG, R. (1977) Clozapine treatment of schizophrenic patients. Acta Psychiatrica Scandinavica. B5. 123-126.

David Taylor, Principal Pharmacist, and Denise Duncan, Drug Information Pharmacist, The Maudsley Hospital, Denmark Hill, London SE5 8AZ

\title{
Treatment of psychotropic-induced hyperprolactinaemia
}

\author{
Denise Duncan and David Taylor
}

Prolactin, a protein hormone synthesised and released by the anterior pituitary, promotes mammary tissue development and lactation and suppresses gonadotrophin secretion. Dopamine is the natural inhibitor of prolactin release and so standard antipsychotics, which block dopamine receptors, will cause prolactin levels to rise. This hyperprolactinaemia can lead to gynaecomastia, galactorrhoea, menstrual disturbances, a reduction in sperm count, erectile dysfunction, failure of ejaculation and reduced libido. Prolactin-related adverse effects are frequently encountered in patients on antipsychotics and are a cause of substantial morbidity.
All antipsychotics except clozapine are associated with hyperprolactinaemia. In the majority of cases the rise in prolactin levels causes few problems. If, however, troublesome adverse effects occur, prolactin serum levels may be reduced by decreasing the dose of antipsychotic or discontinuing treatment. If this is not practicable, limited trial work has supported the use of amantadine or bromocriptine. This is reviewed below.

Amantadine's mechanism of action remains unclear but it is thought to enhance dopaminergic activity by causing a release of dopamine or by direct agonist activity. Because amantadine had been used successfully to treat 
Parkinson's disease while engendering few adverse psychiatric phenomena, it was suggested that it may be successful in decreasing prolactin levels without worsening psychosis. In one study (Siever, 1981), a group of eleven patients (ten women, one man), of whom five had galactorrhoea, were given amantadine at a dose of $100 \mathrm{mg}$ three times a day for two weeks. Prolactin levels were measured in eight of the eleven patients before and after amantadine treatment. Six of these patients showed a reduction although levels still remained above normal. Importantly, all five of the women who had experienced galactorrhoea showed some improvement in their symptoms.

A second study by Correa et al (1987) evaluated amantadine's effect on prolactinmediated side effects in ten patients (six males, four females). Amantadine was given in doses of $200-300 \mathrm{mg} /$ day for three weeks. At the end of this time, prolactin levels had decreased by an average of $21 \%(P<0.0005)$. Weight loss was observed in all ten patients and a decrease in breast tenderness, gynaecomastia, galactorrhoea and sexual dysfunction occurred in all patients who had presented with these adverse effects. Menstruation also returned in the women who had been amenorrhoeic before the study. According to an extrapyramidal rating scale, scores improved for seven out of nine patients. There was a significant but small fall in the overall Brief Psychiatric Rating Scale score indicating that amantadine did not worsen psychosis.

There are also two published studies evaluating the use of bromocriptine, a direct dopamine agonist. In the first (Beumont et al, 1975), bromocriptine was given in a dose of $2.5 \mathrm{mg}$ twice daily to nine female patients to investigate its effects on prolactin levels, galactorrhoea and menstrual disturbances. In all but one of the patients prolactin levels fell but menses returned in only one of the eight patients. Five patients who had pronounced galactorrhoea before the study all experienced a reduction in symptoms. No discernible adverse effects were noted.

A trial published in Japan in which bromocriptine was given in a dose of 5$7.5 \mathrm{mg}$ twice daily was reported in a review by Marken et al (1992). Treatment was generally successful with seven of ten subjects experiencing a return of menses, and several showing an improvement in galactorrhoea. Psychotic symptoms appeared not to be worsened by bromocriptine. A case report (Ramakrishnan et al, 1983) has also described the successful use of bromocriptine, up to $10 \mathrm{mg} /$ day, in reducing prolactin levels and improving symptoms of galactorrhoea and amenorrhoea.

These open, small-scale trials indicate that both amantadine and bromocriptine may lower prolactin levels and improve prolactinrelated adverse effects. Both drugs seem not to worsen psychotic symptoms. Nevertheless, bromocriptine is well known to cause psychosis in patients with Parkinson's disease and amantadine has been reported to cause hallucinations in an elderly patient with moderate renal failure (Borison, 1979). Amantadine may also precipitate mania (Rego et al, 1989).

In conclusion, if adverse effects associated with hyperprolactinaemia present as a serious problem and a reduction in the antipsychotic dose does not help, amantadine or bromocriptine may be helpful. Prolactin levels are usually lowered in a few days but prolactinrelated adverse effects may take weeks to improve. Amantadine should be prescribed at a dose of $100 \mathrm{mg} /$ day for the first week. This can be increased by $100 \mathrm{mg}$ weekly until a dose of $200-300 \mathrm{mg} /$ day is reached. Adverse effects include livedo reticularis and postural hypotension as well as nervousness, insomnia, dizziness, convulsions and hallucinations. If bromocriptine is prescribed it should be started at a dose of $1.25 \mathrm{mg}$ at night. This can then be increased by $1.25 \mathrm{mg}$ every two to three days until a daily dose of between $5 \mathrm{mg}$ and $15 \mathrm{mg}$ is achieved. Common adverse effects include nausea, postural hypotension, dizziness and headache; hallucinations occur rarely. Either drug should be withdrawn if any worsening of psychosis is suspected. Amantadine is not officially licensed for use in hyperprolactinaemia but is perhaps the drug of first choice because bromocriptine is generally held to be contra-indicated in any psychotic illness.

\section{References}

Beumont, P., Bruwer, J., Pimstone, et al (1975) Bromergocryptine in the treatment of phenothiazine-induced galactorrhoea. British Journal of Psychiatry, 126, 285288.

BORISON, R. L. (1979) Amantadine-induced psychosis in a geriatric patient with renal disease. American Journal of Psychiatry, 186, 111-112.

CORREA, N., OPLER, L. A., KAY, S. R., et al (1987) Amantadine in the treatment of neuroendocrine side effects of neuroleptics. Journal of Clinical Psychopharmacology. 7(2), 91-95. 
MARKEN, P. A., HAYKAL, R. F. \& FISHER, J. N. (1992) Management of psychotropic-induced hyperprolactinemia. Clinical Pharmacy, 11, 851-855.

REGo, M. D. \& GILER, E. L. (1989) Mania secondary to amantadine treatment of neuroleptic-induced hyperprolactinemia. Journal of Clinical Psychiatry. EO(4), 143-144.

Shenoy, R. S., Ettigi, P. \& Johnson, C. H. (1983) Bromocriptine in the treatment of galactorrhea caused by haloperidol: A case study. Journal of Clinical Psychopharmacology, 3(3), 187-188.
SIEVER, L. J. (1981) The effect of amantadine on prolactin levels and galactorrhea on neuroleptic-treated patients. Journal of Clinical Psychopharmacology. 1(1). 2-7.

Denise Duncan, Drug Information Pharmacist, and David Taylor, Principal Pharmacist, The Maudsley Hospital, Denmark Hill, London SE5 8AZ

\section{ICD-10 \\ Classification of Mental and Behavioural Disorders}

Published by the World Health Organisation, Geneva

Clinical Descriptions and Diagnostic Guidelines

$£ 28.00,362$ pp., 1992, ISBN 9241544228

Diagnostic Criteria for Research

$£ 28.00,248$ pp., 1993, ISBN 9241544554

Available from the Publications Department, Royal College of Psychiatrists, 17 Belgrave Square, London SW1X 8PG (Tel. 0171-235 2351, extension 146) 